\title{
The economics of algorithmic selection on the Internet
}

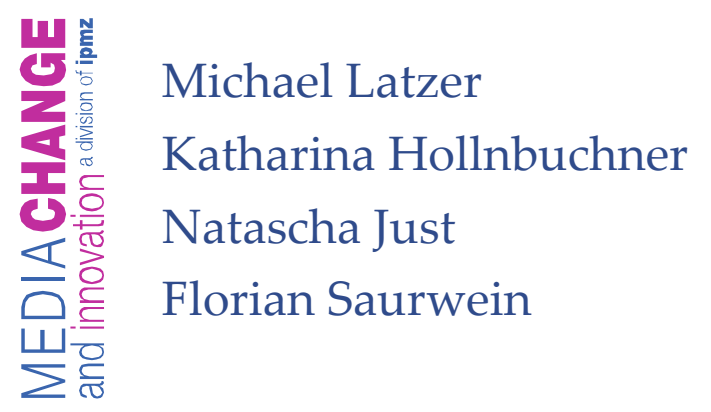

A revised version of this Working Paper is forthcoming in:

Bauer, Johannes/Latzer, Michael eds (2015): Handbook on the Economics of the Internet. Edward Elgar.

October 2014 


\section{Imprint}

\section{PUBLISHER}

University of Zurich

IPMZ - Institute for Mass Communication and Media Research

Media Change \& Innovation Division

Andreasstrasse 15

8050 Zurich

http://www.mediachange.ch

\section{PLEASE QUOTE AS}

Latzer, M.; Hollnbuchner, K.; Just, N. \& Saurwein, F. (2014). The economics of algorithmic selection on the Internet. Working Paper - Media Change \& Innovation Division. University of Zurich, Zurich.

http://www.mediachange.ch/media/pdf/publications/economics_of_algorithmic_selection.pdf

\section{CONTACT}

Prof. Dr. Michael Latzer, m.latzer@ipmz.uzh.ch

This research was supported by a research grant of the Swiss National Science Foundation. 


\section{The economics of algorithmic selection on the Internet}

Michael Latzer, Katharina Hollnbuchner, Natascha Just, Florian Saurwein

Corresponding author:

MichaelLatzer,m.latzer@ipmz.uzh.ch

University of Zurich, IPMZ, Media Change \& Innovation Division

\subsection{Introduction}

Algorithms have come to shape our daily lives and realities. They change the perception of the world, affect our behavior by influencing our choices, and are an important source of social order. Algorithms on the Internet have significant economic implications in newly emerging markets and for existing markets in various sectors. A wide range of our daily activities in general and our media consumption in particular are increasingly shaped by algorithms operating behind the scenes: the selection of online news via search engines and news aggregators, the consumption of music and video entertainment via recommender systems, the choice of services and products in online shops and the selection of status messages displayed on social online networks are the most prominent examples of this omnipresent trend. Algorithms suggest friends, news, songs and travel routes. Moreover, they automatically produce news articles and messages, they calculate scorings of content and people, and are employed to observe our behavior and interests as well as to predict our future needs and actions. By assigning relevance to certain pieces of information they keep consumers, companies and authorities from drowning in a growing flood of information and online data. At the same time, they mine and construct realities, guide our actions and thereby determine the economic success of products and services. Algorithms form the technofunctional basis of new services and business models that economically challenge traditional industries and business strategies. These economic changes and challenges are accompanied by and interact with significant social risks such as manipulation and bias, threats to privacy and violations of intellectual property rights that compromise the economic and social welfare effects of algorithmic selection applications.

This rapidly growing Internet phenomenon is here called 'algorithmic selection'. It is a central and structuring bundle of Internet innovations in digital economies. Algorithmic selection is embedded in a variety of Internet-based services and is applied for numerous purposes. Although their modes of operation differ in detail, all of these applications are characterized by a common basic functionality: They automatically select information 
elements and assign relevance to them. This common feature defines the properties of algorithmic selection and facilitates a formal distinction from other Internet phenomena such as Web 2.0 (O'Reilly 2007), the Internet of things (Ashton 2009; Mattern and Flörkemeier 2010) and big data.

The development of algorithmic selection is closely related to a number of technoeconomic and social trends in information societies, including computerization, big data, personalization, automation and economic optimization. In essence, its diffusion and growing importance is fueled by the combination of ubiquitous computerization and the proliferation of an increasingly mobile Internet. In a growing number of economic and social domains, the spread of algorithmic selection is driven by the diffusion of online information, communication and transactions. Computers and the Internet serve as enabling technologies that provide the infrastructure - the technological and functional precondition for a wide range of applications. At the same time, ubiquitous computerization and Internet use generate additional demand for algorithmic selection, because they result in a massive proliferation of data volumes and a growing need for orientation by selection. These (big) data form the raw material (World Economic Forum 2011a) for algorithmic selection, create economic opportunities and call for data/reality-mining tools in order to harness the economic opportunities. Altogether, the combination of technological, data-based opportunities and economic demand for selection is a major driver for the establishment of new industries, applications and business models, where automation of data processing plays a central role, and algorithmic selection perfectly supports business strategies, especially in terms of process optimizations. Automated algorithmic selection advances optimizations in various ways: faster processing of larger amounts of data by automation; cost reductions in production and transmission by automation of data processing; strategic enhancements by increased datadriven, evidence-based decision-making (McAfee and Brynjolfsson 2012); and personalization by mass-customization of products and services that are tailored to meet diverse consumer needs.

With a high potential for economic improvement, algorithmic selection services are spreading fast in a wide range of industries. As argued for big data (OECD 2013), their diffusion is especially high in sectors characterized by a high degree of digitization and high data intensity. Accordingly, it already plays a major role in industries that rely heavily on digital production and online transmission such as Internet search, news, advertising, entertainment and social online networks. Further, algorithmic selection has gained importance in areas such as retail, trade, the stock exchange, banking, insurance, politics, 
security, intelligence, transportation, logistics, science, education, health, and employment (Latzer et al. 2014). Given the combination of ubiquitous computerization, rapidly growing amounts of available data, and economic pressure for optimizations, the trend towards increased algorithmic selection in a rising number of domains seems to be irreversible. This provides the starting point and the rationale for more in-depth analyses on the characteristics, role and consequences of algorithmic selection for markets and societies.

Most social-science research on algorithms has focused on search engines (Varian 2006; Machill and Beiler 2007; Lewandowski 2012; König and Ramsch 2014) and recommendation systems (Resnick and Varian 1997; Senecal and Nantel 2004; Klahold 2009; Jannach et al. 2011; Ricci et al. 2011; Robillard et al. 2014). This paper extends the scope of analysis and provides a comprehensive overview of this phenomenon, with a special focus on how to think economically about algorithmic selection. It explores the characteristics and implications of a rapidly growing Internet phenomenon that automates nothing less than the commercialization of reality mining and reality construction in information societies. The following questions are tackled: How can the plethora of algorithmic selection applications on the Internet be analytically grasped and categorized? How does algorithmic selection operate and where is it applied? What market structures and business models are evolving and how do they affect existing media markets? What are the major social and economic benefits and risks of algorithmic selection, and what governance choices are available to minimize risks and thus maximize economic and social welfare?

The paper proceeds as follows: The next section offers a typology of algorithmic selection applications and provides a basic input-throughput-output model in order to show the functioning and economic purposes of the different types of algorithmic selection. Section three explains the theoretical perspective applied for its analysis. Section four presents results from market analyses and shows the different market phases of algorithmic-selection markets, explores market structures and explains concentration tendencies. Section five provides insights into business models of algorithmic selection with an emphasis on value proposition, value creation and revenue streams. Section six examines selected implications of algorithmic selection for traditional media markets and the incumbents' profitability. Section seven identifies areas of risk, such as the violation of basic rights, the changing perception of the world and the impact of algorithmic selection on human development. Finally, section eight summarizes regulatory challenges and discusses opportunities and limitations of available governance choices such as market solutions, self-regulation and state intervention. Section nine draws conclusions about the economics of algorithmic selection. 


\subsection{The operation model and functional typology}

Algorithmic selection is applied for a number of purposes. It is the technological basis or functional feature of many of the most popular and economically successful Internet services, among other things, by Google, Facebook, Amazon, Netflix or Spotify. Applications and groups of services based on algorithmic selection often contain prefixes such as 'algorithmic' or simply 'algo' (e.g., algo trading), 'computerized' or 'computational' (e.g., computational advertising), 'smart' or 'intelligent' (e.g., intelligent filtering). This plurality of applications, services and terms constitutes a challenge for research. In order to explore algorithmic selection it has to be defined and distinguished from other phenomena. Moreover, it is helpful, to differentiate certain groups of applications in order to compare and contrast functions, markets and risks associated with certain types of application.

Although there are infinite definitions of algorithm, it can generally be described as a finite series of precisely described rules or processes to solve a problem. It is a sequence of stages that transforms input through specified computational procedures (throughput) into output (Cormen et al. 2009; Mössenböck 2014). Generally, all algorithmic selection applications can be described with the help of a basic input-throughput-output model (I-T-O), depicted in Figure 1.1.

Figure 1.1: Input-Throughput-Output model of algorithmic selection on the Internet

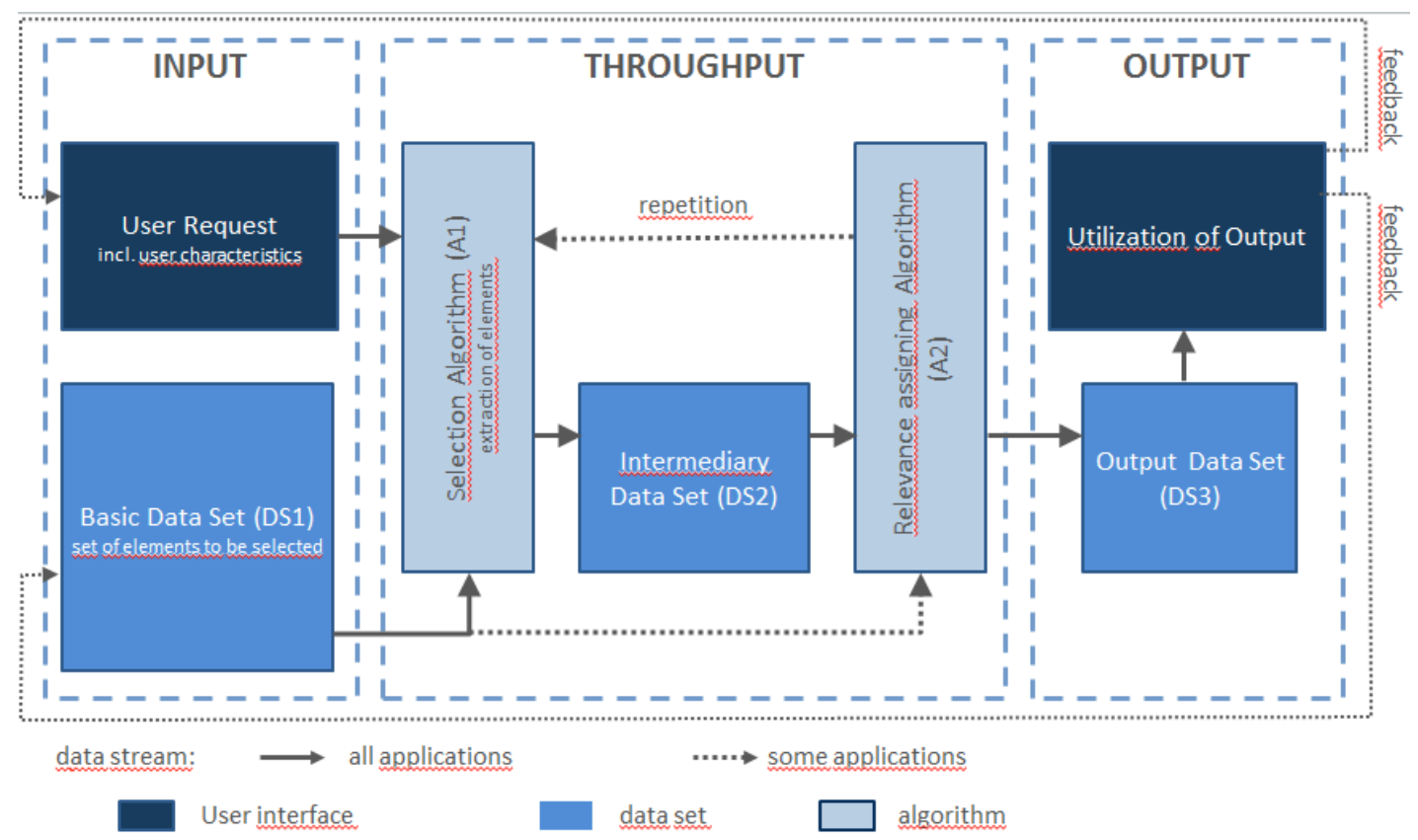

Source: Based on Latzer et al. 2014 
The centerpiece of this process model is the throughput stage where the algorithms operate that define the input-output relationship. Starting from a user request and available user characteristics they apply statistical operations to select elements from a basic data set (DS1) and assign relevance to them. Accordingly, algorithmic selection on the Internet is defined as a process that assigns relevance to information elements of a data set by an automated, statistical assessment of decentrally generated data signals. In detail, input, throughput and output vary for different applications and services. In many cases, big data serve as input, but there is a wide spectrum of input sources, depending on the field of application. The throughput process is characterized by the assignment of relevance (A2) and respective selections (A1), and there is a multitude of different codes based on different operating modes (e.g., matching, sorting or filtering algorithms). Finally, the output (DS3) also takes on different forms (e.g., rankings, recommendations, biddings, text, music). In many cases, it also serves as an additional input for subsequent algorithmic selection processes.

Applications can be differentiated according to their central function, i.e. the general purpose that these applications serve. Here, a functional typology is proposed that covers nine categories (Table 1.1). It should be kept in mind, though, that these categories are neither meant to be all-embracing nor mutually exclusive. 
Table 1.1: Functional typology of algorithmic selection applications

\begin{tabular}{|c|c|}
\hline Type & Examples \\
\hline search applications & $\begin{array}{l}\text { general search engines (e.g., Google search, Bing, Baidu) } \\
\text { special search engines (e.g., genealogy: Mocavo, pictures: Shutterstock, social } \\
\text { media: Social Mention) } \\
\text { meta search engines (e.g., Dogpile, Info.com) } \\
\text { semantic search engines (e.g., Yummly) } \\
\text { questions \& answers services (e.g., Ask.com) }\end{array}$ \\
\hline aggregation applications & news aggregators (e.g., Google News, nachrichten.de) \\
\hline observation/surveillance applications & $\begin{array}{l}\text { government/intelligence surveillance (e.g., Raytheon RIOT) } \\
\text { monitoring of corporate/private ICT infrastructures and usage (e.g., Spector, } \\
\text { Spytec, Splunk) } \\
\text { detection of illegal content (e.g., PhotoDNA for child pornography) }\end{array}$ \\
\hline prognosis/forecast applications & $\begin{array}{l}\text { predictive policing (e.g., PredPol), predictive profiling } \\
\text { predicting developments: e.g., success of music (scoreAhit, Music Xray), } \\
\text { diffusion of diseases (Google Flu Trends) }\end{array}$ \\
\hline filtering applications & $\begin{array}{l}\text { spam filter (e.g., Norton) } \\
\text { child protection filter (e.g., Net Nanny) }\end{array}$ \\
\hline recommendation applications & recommender systems: e.g., for music (Spotify), films (Netflix) \\
\hline scoring applications & $\begin{array}{l}\text { reputation systems: music, film, etc. (e.g., ebay's buyer/seller reviews) } \\
\text { news scoring (e.g., reddit, Digg) } \\
\text { credit scoring (e.g., Creditkarma) } \\
\text { social scoring (e.g., Klout) }\end{array}$ \\
\hline content production applications & algorithmic journalism (e.g., Quill; Quakebot) \\
\hline allocation applications & $\begin{array}{l}\text { computational advertising (e.g., Google AdSense, Yahoo! Bing Network) } \\
\text { algorithmic trading (e.g., Quantopian) }\end{array}$ \\
\hline
\end{tabular}

Source: Based on Latzer et al. 2014

Search applications have become indispensable tools for exploring the Internet and are the most widespread algorithmic services with great economic significance. Relevance is assigned to elements according to the best fit with user's queries. Alongside general-purpose algorithmic search engines such as Google and Bing, there is a vast number of applications for special (vertical) searching in particular domains or regarding particular issues (e.g., Mocavo, a genealogy search engine). General search engines play an important role in the growing branch of e-commerce, which has led to the development of connected industries of web-content production and website optimization (known as search engine optimization, SEO, agencies) as well as search engine marketing specialists (SEM). The gatekeeping role of general search engines and especially the dominant market position of Google are highly contested issues in the public debate.

Aggregation applications, most prominently news aggregators such as Google News, collect, categorize and regroup information from multiple sources into one single point of access (Zhu et al. 2001; Águila-Obra et al 2007; Calin et al. 2013). Unlike syndicators, aggregators often acquire the data they offer (e.g., news) without paying. This business model has attracted severe criticism and debate, especially regarding the impact on the profitability 
of other media industries (in particular newspapers) and alleged intellectual property rights violations (Isbell 2010; Weaver 2013).

Observation/surveillance applications such as Raytheon's Rapid Information Overlay Technology (RIOT) have gained prominence lately and were heavily criticized in the context of the NSA scandal (Greenwald and MacAskill 2013). Not only do secret-service agencies make use of algorithmic surveillance, but companies also employ surveillance technologies, for example, for social sorting (Lyon 2003), to control their networks, employees (Ciocchetti 2011) and customers (Pridmore and Zwick 2011). Many applications monitor online behavior in order to detect abnormalities associated with certain risks (e.g., credit-card fraud, cyber attacks). Moreover, for several other algorithmic applications, such as forecasting services or computational advertising, observation and surveillance are a basic function.

Prognosis/forecast applications aim at predicting future behavior or scenarios (Küsters et al. 2006; Issenberg 2012; Silver 2012), for instance, in areas such as consumption, natural disasters, entertainment hits and crime. Respective applications, such as the predictive policing technology PredPol are of particular importance in the context of big data analyses. The distinction between surveillance applications and forecast applications is often not clearcut, as both employ similar data/reality mining methods, or are applied in combination. To distinguish them, surveillance applications are sometimes called 'now-casting' applications (Banbura et al. 2010; Faigle 2010), which points to time as differentiating factor. Surveillance refers to the present (real time), while forecasting relates to future occurrences.

Filtering applications such as the Norton spam filter often work behind the scenes as passive or active information filters (Hanani et al. 2001). Passive filters select certain elements, but instead of displaying these to the user, they prevent access to them. Algorithmic or intelligent filtering is applied, for instance, to counter spam or malware. However, filtering is also used to block political information, especially in authoritarian regimes (Deibert et al. 2008, 2010).

Recommendation applications such as music recommendations by Spotify are among the most widely known services. These online applications are intended to replace traditional recommendations by shop assistants or friends. To provide the most fitting recommendations they apply various filtering methods relying on data concerning the item, the user, or the artificial group a user is assigned to (Klahold 2009). Recommender systems are very common in e-commerce and play an important role for increasing sales by reducing search costs and building e-trust (Pathak et al. 2010). 
Scoring applications such as eBay's reputation system gather and process feedback about participants' behavior and derive ratings and scores relating to behavior from this (Resnick and Zeckhauser 2002). A central purpose of these services is to build trust in an anonymous online environment and reduce transaction costs. Applications include sensitive areas such as credit scoring (Rothmann et al. 2014) or social scoring (measuring a person's creditworthiness or social resources). Accordingly, these systems involve considerable risks of social discrimination on the grounds of a person's race, age or religion and may infringe personal privacy (Bostic and Calem 2003; Pavlov et al. 2004; Steinbrecher 2006).

Furthermore, algorithms can be used to create content automatically, for example, with applications such as Quill, developed by Narrative Science. These developments have recently been discussed under terms such as algorithmic, automated or robotic journalism (Levy 2012; Steiner 2012; Anderson 2013; Wallace and Dörr 2015). Automated production is not limited to text (e.g., tweets, news articles, business reports) but music production is affected as well. It allows for massive content production and contains the potential for the further rationalization and commercialization of media production. These applications touch deeply upon human areas of creativity and expression, leading to a revival of discussions about artificial intelligence software.

Allocation applications independently and automatically conduct transactions (e.g., placement of ads) and allocate resources (Lee 2007; Varian 2009; Leinweber 2009). Algorithmic trading software or computational advertising services such as Google AdSense are good examples of such applications. Computational advertising especially is the core revenue source for many online platforms such as search and social online networks (Evans 2008).

\subsection{The innovation-co-evolution-complexity perspective}

The Internet is a multipurpose infrastructure for innumerable and highly diverse applications. This considerably limits the prospects of deriving generalized economic consequences. The identification and focus on one distinct set of Internet-based innovations - algorithmic selection - is an effort to take a more differentiated look at its economic and social implications. Other analytical challenges are the great significance of technological change and its interplay with economic, political and social transformations.

This paper starts from an integrated innovation-co-evolution-complexity perspective (Latzer 2013a), which conceives media change as an innovation-driven, co-evolutionary 
process in a complex environment, marked by adaptive, non-linear system behavior. Algorithmic selection by search engines and recommendation systems on the micro-level, for example, result in unpredictable, unintended emergent effects on the link structure of the WWW at the macro level. Accordingly, the Internet is understood as an open adaptive system, an 'innovation machine' because of its specific (end-to-end) architectural design (Whitt and Schultze 2009; Van Schewick 2010). Co-evolution - sometimes addressed as coconstruction or confluence (Benkler 2006) - is a durable relation between agents that influence each other's evolutionary paths. Hence, according to a complexity economics perspective (Beinhocker 2006), processes in economics, politics, technology and society are driven by mutually selective pressure or adaption. This explains the reciprocal interplay more precisely the pressure and adaptive behavior of technology, organizations and business models that nurture each other. The advantages of such a co-evolutionary perspective include its contribution to better understanding and integrating evolutionary technological change (Ziman 2000) - where technology is not only output but also input into the economy; to overcome the antagonism of technological and social determinism (Rip 2007), and to direct the focus from static assessments to dynamic approaches. Finally, such a co-evolutionary perspective results in other (adaptive) strategies for media management and governance than traditional approaches alone, due to an acknowledgement of the limited predictability and steerability of dynamic co-evolutionary developments (Latzer 2013b, 2014).

Selecting and relevance-assigning algorithms on the Internet can be understood, with reference to Bresnahan (2010), as micro general-purpose technologies, as widely used clusters of (radical) innovations that enable and trigger innovations in many other economic sectors, because they offer not one specific solution but various new opportunities. The coevolution with political, economic and cultural factors determines what opportunities will ultimately be used and what the consequences will be for socio-economic welfare. Governance activities to minimize risks - discussed below - are closely interlinked with economic factors and also interact with technological characteristics.

Algorithmic selection can lead to creative destruction, and has even the potential to be a disruptive technology (Christensen 1997), a special form of creative destruction marked by inferior technology and the replacement of incumbents (low-end disruption, e.g., credit scoring, and new market disruptions, e.g., computational advertising). Innovations are coevolutionary, adaptive processes of renewal, marked by variation, selection and adaptive reactions. Corporations play a crucial role in selection processes of technologies and of 
appropriate business models. This will be described in the following sections of this paper, together with other characteristics of algorithmic selection markets and their market phases.

Starting from an innovation-co-evolution-complexity perspective, several other approaches help to better understand algorithmic selection. The power of technology and the ability of algorithms to shape realities and societies has been variously discussed by researchers and journalists who focus, among other things, on the role of algorithms as agents (Machill and Beiler 2007), institutions (Napoli 2013), ideologies (Mager 2012) and gatekeepers (Jürgens et al. 2011; Wallace and Dörr 2015). An institutional point of view, for example, highlights the enabling and restricting role of technologies in general and of algorithms in particular.

Further, algorithmic selection can be conceived as a mode of intermediation (ÁguilaObra et al. 2007), which is central, for example, to understanding platforms and multisided markets. It connects supply and demand, i.e. providers and consumers of products and content. Algorithms are involved in the allocation of resources, and often have the role of market makers in the value-creation system - discussed below. Additionally, the intermediation perspective highlights the role as gatekeeper and its effects on the public sphere and public-opinion formation as well as its role in the algorithmic construction of realities.

\subsection{Markets, market phases and structures}

Algorithmic selection is creating new Internet-based markets and changing existing ones on a large scale. It can constitute the (economic) core function of Internet-based services, for example in the case of the general search services of Google or Microsoft, and/or it is applied as an ancillary function, for example in e-commerce applications for filtering/recommendation purposes by Amazon, or for the automated selection of status messages displayed in online social media applications by Facebook. Core function basically means that the result of algorithmic selections is the demanded product; ancillary functions are used to support the core service of a company in order to gain competitive advantage.

Altogether, almost all of the most popular and economically successful Internet-based services rely heavily on algorithmic selection in one form or another. Table 1.2 shows the ten most visited websites worldwide in 2014 and their applications based on algorithmic selection as a core and/or ancillary service. Seven of these rely heavily on computational advertising, and four on general search engines. Three websites use algorithmic selection as an ancillary 
service only (Wikipedia and two online-shopping platforms). Further, the dominance of US (7) and Chinese (3) companies is striking.

Table 1.2: Algorithmic selection in top 10 websites worldwide

\begin{tabular}{|c|c|c|c|c|}
\hline Ranking & Website & $\begin{array}{l}\text { Company and } \\
\text { country of origin }\end{array}$ & $\begin{array}{c}\text { Algorithmic Selection as } \\
\text { Core Service }\end{array}$ & $\begin{array}{c}\text { Algorithmic Selection as } \\
\text { Ancillary Service }\end{array}$ \\
\hline 1 & google.com & Google (USA) & $\begin{array}{l}\text { general search engine } \\
\text { computational advertising }\end{array}$ & autocomplete \\
\hline 2 & facebook.com & Facebook (USA) & computational advertising & $\begin{array}{l}\text { filtering (EdgeRank) } \\
\text { social search (GraphSearch) } \\
\text { recommendations (contacts) }\end{array}$ \\
\hline 3 & youtube.com & Google (USA) & computational advertising & $\begin{array}{l}\text { recommendations (videos) } \\
\text { special search engine }\end{array}$ \\
\hline 4 & yahoo.com & Yahoo (USA) & $\begin{array}{l}\text { general search engine } \\
\text { computational advertising }\end{array}$ & autocomplete \\
\hline 5 & baidu.com & Baidu (CHN) & $\begin{array}{l}\text { general search engine } \\
\text { computational advertising }\end{array}$ & autocomplete \\
\hline 6 & wikipedia.org & $\begin{array}{l}\text { Wikimedia } \\
\text { Foundation (USA) }\end{array}$ & & special search engine \\
\hline 7 & twitter.com & Twitter (USA) & computational advertising & $\begin{array}{l}\text { recommendations (Twitter Trends, } \\
\text { Who to Follow) }\end{array}$ \\
\hline 8 & qq.com & Tencent (CHN) & $\begin{array}{l}\text { general search engine } \\
\text { computational advertising }\end{array}$ & autocomplete \\
\hline 9 & taobao.com & $\begin{array}{l}\text { Alibaba Group } \\
(\mathrm{CHN})\end{array}$ & & $\begin{array}{l}\text { special search (products) } \\
\text { recommendations (products) } \\
\text { reputation (marketplace sellers) }\end{array}$ \\
\hline 10 & amazon.com & Amazon (USA) & & $\begin{array}{l}\text { special search (products) } \\
\text { recommendations (products) } \\
\text { reputation (marketplace sellers) }\end{array}$ \\
\hline
\end{tabular}

Source: Own, Ranking based on alexa.com, 15-07-2014

Despite variations between different categories, market sizes tend to be high (e.g., search, computational advertising) and growth rates impressive (e.g., music and film streaming) for services and products based on algorithmic selection.

Markets pass through different phases in their life cycles: from experimental and expansion phases to maturity, stagnation and decline. Accordingly, they show different market structures, sizes and growth rates, and call for different business strategies and public policies. Based on a review of available market data, a rough appraisal of various types of algorithmic selection by market phases can be given. Most types are still in an experimental (e.g., algorithmic prognosis of the future success of films and music) or an early expansion phase (e.g., automated content production; scoring; surveillance) with comparatively low market sizes as yet, which can be expected to grow significantly in coming years. Examples of the expansion/growth phase are recommender systems for music and films (e.g., Spotify, Netflix) with high annual growth rates. Computational advertising markets can roughly be 
classified within the maturity phase, and general search markets are already tending toward stagnation, with decreasing growth rates but impressive market sizes. These latter two categories show high concentration rates. Search markets are highly concentrated on a global scale, with regional market shares of Google Search up to $97 \%$ (see Table 1.3). The major display-ad-selling companies are Google and Facebook, which in 2013 possessed US ad revenue shares of $17.6 \%$ and $14.6 \%$ respectively. These shares are estimated to grow to $24.6 \%$ for Google and $15.5 \%$ for Facebook in 2015, resulting in a concentration ratio CR2 of 40.1\% (eMarketer 2013). Concentration is not only evident for search and computational advertising. The leading US dating platform, for example, is match.com (Statista, June 2014), a brand belonging to InterActiveCorp (IAC), which in 2012 had a 41\% US market share in online dating with its portfolio of online dating services, with the CR2 in online dating amounting to $64 \%$ (VanderMey 2013).

Table 1.3: Concentration of search engine markets in selected countries, Europe and worldwide, (end of 2013)

\begin{tabular}{|c|c|c|c|c|c|}
\hline & $\begin{array}{c}\text { Google } \\
\text { (USA) }\end{array}$ & $\begin{array}{l}\text { Yahoo } \\
\text { (USA) }\end{array}$ & $\begin{array}{l}\text { Bing } \\
\text { (USA) }\end{array}$ & $\begin{array}{l}\text { Baidu } \\
(\mathrm{CHN})\end{array}$ & $\begin{array}{c}\text { Yandex } \\
\text { (RUS) }\end{array}$ \\
\hline Thailand & $97.0 \%$ & & & & \\
\hline Spain & $96.3 \%$ & $0.9 \%$ & $1.1 \%$ & & \\
\hline Vietnam & $96.0 \%$ & & & & \\
\hline United Kingdom & $94.2 \%$ & $1.8 \%$ & $2.7 \%$ & & \\
\hline Germany & $94.1 \%$ & $0.8 \%$ & $1.6 \%$ & & \\
\hline France & $92.8 \%$ & $1.7 \%$ & $2.6 \%$ & & \\
\hline India & $90.0 \%$ & & & & \\
\hline Indonesia & $88.0 \%$ & & & & \\
\hline Malaysia & $87.0 \%$ & & & & \\
\hline Philippines & $84.0 \%$ & & & & \\
\hline Singapore & $84.0 \%$ & & & & \\
\hline USA & $67.3 \%$ & $10.8 \%$ & $18.2 \%$ & & \\
\hline China & $1.7 \%$ & $0.3 \%$ & $0.6 \%$ & $63.6 \%$ & \\
\hline Russia & $26.5 \%$ & & & & $61.9 \%$ \\
\hline Japan* & $36 \%$ & $51.4 \%$ & & & \\
\hline \begin{tabular}{|lr} 
Europe* $^{*}(18$ \\
countries incl. RU)
\end{tabular} & $86.0 \%$ & & $1.0 \%$ & & $10.0 \%$ \\
\hline Worldwide* & $65.2 \%$ & $4.9 \%$ & $2.5 \%$ & $8.2 \%$ & $2.8 \%$ \\
\hline
\end{tabular}

Sources: ComScore 2013/2014 (Europe, ID, IN, MY, PH, SG, TH, US, VN), Bloomberg 2013 (RU), CNZZ 2013 (CN), Schautzer 2013 (JP), AT Internet 2014 (DE, ES, FR, UK), Sullivan 2013 (worldwide); * 2012 data

Concentration tendencies are a constituent feature of many of the Internet businesses that offer products and services that operate on algorithmic selection. Many of these can be described as two- or multisided platforms, operating on two- or multisided markets (Rochet and Tirole 2003) - a characteristic that has important interrelated economic, business and policy implications. In such cases, for example, the platform acts as an intermediary, as a 
market maker, between (at least) two demand sides that are interlinked by indirect network effects, which may be one reason for concentration in these markets.

These concentration tendencies can be explained by various industrial economic characteristics such as cost structures, scale and scope economies, direct and indirect network effects. As with traditional media markets, cost structures for algorithmic selection markets are characterized by considerable economies of scale, resulting from high fixed and sunk cost (e.g., R\&D, hardware and software maintenance), and extremely low marginal cost of additional selection processes (e.g., an additional music recommendation). Hence dominant players produce most efficiently, resulting in high market entry barriers due to efficiency deficits of new entrants. A large market size is often necessary to operate efficiently, an issue that is also evident when considering indirect network effects that arise when the number of participants on one side (positively or negatively) affects the number of participants on the other. Usually the participation of one group raises the value of participating for the other group. For example, the more users a search engine has, the greater the positive indirect effects on advertisers. Although advertising might be a nuisance for users, both sides need to join the platform for success - a task usually accomplished through the pricing structure, where a higher price is typically paid on the side that generates less positive network effects.

This leads to another important characteristic: algorithmic selection markets are predominantly characterized by quality and innovation competition and less by price competition. Many applications are free of charge for end customers. Hence the perceived quality of a service is particularly important for gaining competitive advantage. The quality of service depends, inter alia, on the quality of algorithms, hardware (e.g., server farms) and (input) data (Argenton and Prüfer 2012). Exclusive access to data by service suppliers who create data (e.g., social media companies) results in a strong competitive advantage. These data form an essential input for selection processes, and might lead to exclusive quality improvements on the input side, thus contributing to concentration tendencies.

Moreover, exclusive access to user and usage data of one's own service results in a competitive advantage for established players and forms a market-entry barrier for newcomers, because they will not be able to offer services of a comparable quality. In contrast to traditional media markets, the quality of services - in essence, the quality of selections - increases with the growing use of a service. The reason is that the results of earlier selections feed back into future selection processes and thus increase their quality. The quality of selections depends, inter alia, on the number of earlier selections, which is why more users and usage result in quality improvements of services. This is true for individual 
users (by improved personalization/customization of products that also increases users' switching costs) and all other users as well. There are network effects, in other words demand-side scale effects. In addition, there is a positive feedback loop between network effects on the demand side and scale effects on the supply side. This again results in concentration tendencies, even in winner-takes-all markets with widening disparities.

Finally, concentration and market entry barriers are facilitated by considerable economies of scope, resulting from multiple exploitation of central resources, in particular of technological know-how - especially on algorithms, of hardware infrastructures and databases. Accordingly, many big players such as Google, Microsoft and Amazon are diversifying and offering a range of different types of algorithmic selection services, thus exploiting economies of scope. Among other things, Google offers search, advertising, aggregation and recommendation, Microsoft is active in search, advertising, surveillance, prognosis and aggregation, IBM in prognosis and surveillance.

Moreover, there is a connection between market phases and market structures. Many algorithmic selection applications are still in the experimental phase or an early expansion phase. These phases are, in general, characterized by high concentration, by temporary monopolies of innovators and early movers. In these early phases, innovators (often US companies in the case of algorithmic selection) also find favorable conditions to export and dominate markets abroad (e.g., Netflix).

\subsection{Business models of algorithmic selection}

Innovation theory suggests that potential benefits of technical innovations can best be exploited in combination with appropriate social/organizational innovations. Among such social innovations are business models that have long 'been given short shrift in the innovation literature' (Teece 2006, p. 1142), however. Awareness of the importance of business models has increased recently, not least because of the growth of the Internet, which both challenged and destroyed traditional business models and opened up debates about how to make money in an online environment that is characterized by expectations that services should be free (Teece 2010). Business models systematically describe the value proposition, the value creation as well as the revenue streams and cost structures (Osterwalder et al. 2005, Jaeggi 2010). They not only focus on companies' products and services, but also on core resources and activities that are needed to create value, and on the channels of delivery to customers. 
Comparative business model analyses of algorithmic selection applications show common patterns for such services. Similarities are mostly found in services offered to end users, resulting in part from market characteristics (e.g., pricing in two- or multisided markets) or from imitation strategies in business models of similar services, whereas services for business and public service customers (e.g., the police) vary more widely, as they are frequently custom-made for specific purposes (Latzer et al. 2014).

\subsubsection{Value proposition}

Value propositions of suppliers of algorithmic selection applications reveal economic and social benefits for individuals, corporations, administrations and society. Among the economic benefits are reductions in transaction costs, cost and performance advantages, and customized problem-solving solutions (Klingenberg 2000; Zollenkop 2006). Predominantly, algorithmic selection promises to reduce various kinds of transaction costs, e.g., search and information costs - mostly in the case of search, filter, aggregation, and recommender applications - or information asymmetries, for example, through reputation systems. A reduction of transaction costs is also realized with allocation services (e.g., computational advertising and advertising networks, algorithmic trading) by mass-customized process automation and by replacing manpower by algorithms. The last of these is also evident in certain areas of content production (e.g., algorithmic journalism). In such cases, efficiency gains may be used differently by companies: to save costs or to increase the quality of other segments of content production, e.g., in the case of algorithmic journalism (van Dalen 2012). Various studies show that the reduction of search costs results in increased consumption and sales, e.g., increased news consumption because of news aggregators (Athey and Mobius 2012; Chiou and Tucker 2013), increased TV consumption due to recommender systems (Pronk et al. 2009), or increased sales because of search and recommender systems in online stores (Hinz and Eckert 2010).

Cost and performance advantages are especially manifest for business and public service customers. In particular, for services in categories like surveillance and prognosis, as well as allocation and content production, algorithmic processing of big data offers advantages to corporate customers and public authorities. For example, computational advertising reduces losses due to personalization and pay-per-click possibilities, algorithmic trading services enter huge amounts of orders at a faster pace than humans, or predictive policing applications are useful in coordinating processes (e.g., stationing of policemen in 
crime-prone areas). The possibilities of enhanced personalization and customization in particular are the basis of many customized solutions provided to customers by algorithmic selection services.

Social benefits of algorithmic selection services include their contribution to social orientation, information gathering and public-opinion formation. News aggregators (e.g., Google News, nachrichten.de), general search engines (e.g., Google, Bing), news-scoring applications (e.g., Reddit, Digg), automated content production and social online networks are expected to contribute to these social benefits.

\subsubsection{Value creation}

Various resources, skills and activities are needed to deliver value to consumers. Within the value creation system of algorithmic selection services there are core resources that are of particular relevance regarding the quality and thus competitive advantage of automated selection processes: technical expertise, especially regarding software/algorithms, the hardware infrastructure (e.g., server farms, computer networks) and access to and quality of data (information elements and externally produced data signals - see Figure 1.1). These influence the value-production chain, including $\mathrm{R} \& \mathrm{D}$, data collection (input), selection processes (throughput) and the use, placement and distribution of selection results (output).

Providers of algorithmic selection applications fulfill different roles within the external value creation system (Heuskel 1999). Analyses indicate that they are most frequently active as market makers (intermediaries) or layer players (specialists), and less as orchestrators that outsource various stages of the value chain, yet occupy strategic position (e.g., Yahoo), or as integrators that integrate nearly all stages of the value chain in their companies (e.g., Google).

As platforms, in particular as market makers between suppliers and consumers (e.g., search engines, news aggregators, advertising networks, music and film streaming), they create new activities within the value chain and bring together products of different companies and offer those, or a selection, to potential customers. Based on this platformization of markets, these services increase transparency (e.g., comparability) and influence customer choice (decisions). Most of the algorithmic selection services directed at end users are active as market makers within the value-creation chain.

Another group of algorithmic selection services, the layer players, specialize in one particular stage of the value chain, which often results in superior knowledge and scale 
effects. They fulfill this stage for individual companies, for a specific sector or across various sectors. Examples include surveillance, security, prognosis and content-production services.

For algorithmic selection applications, not only the various undisclosed algorithms but also the supply and the quality of selection elements and data signals are crucial for competitive advantages and economic success. There are different types of suppliers of selection elements: suppliers based on contracts who are financially compensated (e.g., music labels that license music for streaming services); customers who provide the data to service suppliers (e.g., police for predictive policing applications); and suppliers whose content is mostly used, some would say appropriated without approval and compensation (e.g., websites of newspapers). Such appropriation of content has raised serious concerns by competitors as it directly affects their profitability (see below). Finally, value creation by algorithmic selection is based, among other things, on the assessment of decentralized data signals in order to assign relevance to information elements (see Figure 1.1). Suppliers of decentralized data signals are, for example, Internet-based services that deliver user data with the consent of users, customers of services that provide data either by consent or unintentionally because they are unwittingly being tracked, and data companies that collect and sell different kinds of data (e.g., sports statistics, historic weather data).

\subsubsection{Revenue models}

Revenue models focus on the sources of revenue and on price setting. They are strongly influenced by the fact that algorithmic selection applications often serve different, interdependent customer segments in two- or multi-sided platform markets, where prices have to be weighted accordingly. As a consequence, in many cases the basic algorithmic selection services for end users are cross-subsidized, typically by advertising. Most search and social online networks, for example, offer their product for free to end users and charge the other side of the market, e.g., the advertisers, for access to them. Computational advertising has now developed into a very sophisticated way to reach target groups, among other things with the help of auctions. In contrast, most applications directed only at business and public service customers (e.g., security, prognosis) serve independent customer segments, and are therefore not usually constrained by price-setting strategies required in multi-sided markets.

Indirect forms of revenue, both transaction-dependent and -independent, predominate in algorithmic selection markets, and direct transaction-dependent forms are rare. There are many indirect transaction-dependent forms of revenue generation, such as pay per click or 
impression ads, Powerplay campaigns (e.g., LastFM) or Promoted Tweets. In many cases revenue is generated from a combination of different sources, however. This can be exemplified with various freemium services like Spotify or LinkedIn. Often a basic service with limited features, usage restrictions, or offered in exchange for advertising - is free to the user, who is charged a premium, however, for services with added functionality, quality and no restrictions. Premium profiles are then a form of direct transaction-independent source of revenue, as are various subscription-only services like Netflix.

\subsection{Selected implications of algorithmic selection for traditional media markets}

The economic implications of algorithmic selection services are as wide as its fields of application in various sectors of the economy. This section focuses on media markets only, in particular on media incumbents' profitability. For decades traditional news companies have dominated the construction of public spheres. They were unchallenged and made high profits in advertising markets. Now, both core businesses of news companies - the audience and advertising markets - are increasingly coming under pressure from activities of IT companies like Microsoft or dot-coms like Google or Yahoo. As market makers, they squeeze themselves between traditional news companies and their two customer segments, the audience and the advertisers (Águila-Obra et al. 2007). Their competitive advantages result from the generation of huge amounts of data and the automated algorithmic selection and placement of news, on the one hand, and from the automated selection and placement of advertisements on the other. News aggregators (e.g., Google News or Bing News) and online advertising networks (e.g., Google AdSense) are examples of such intermediaries.

Research on the impact of algorithmic selection on media industries predominantly focuses on news aggregators and online advertising, revealing that they increase both the reading consumptions and the quality of news (e.g., Athey and Mobius 2012; Chiou and Tucker 2013; Dellarocas et al. 2013) and have impacts on price strategies and targeting methods in online and offline advertising markets (Edelmann et al. 2005; Evans 2009; Bergmann and Bonatti 2011). Many other questions remain unanswered and call for further research, especially those regarding the combined economic impact of various algorithmic selection applications that affect both the audience and the advertising market. Moreover, the impact of algorithmic selection on other media industries such as music or film has not yet been examined. 
A basis for such analysis is Porter's (2008) concept of five forces that shape industry competition, which has been applied, for example, by Maaß et al. (2009) to assess the robustness of concentration in search markets. Coupled with comparative analyses of business models and market structures, Porter's approach also makes it possible to assess the impact of algorithmic selection applications such as news aggregators, algorithmic content production, computational advertising, music streaming or subscription video-on-demand services on the news, music, film and TV industries. Changes to the five competitive forces - the threat of new entrants and of substitute products and services, the bargaining power of both suppliers and buyers, and the rivalry among existing competitors - affect the average profitability of media incumbents.

Theoretical considerations suggest that algorithmic selection services predominantly come into effect as intermediaries or suppliers in media industries, and tend to change its profitability. In his overall assessment of the Internet, Porter (2001) argues that the Internet tends to decrease profitability. Theoretical analyses of algorithmic selection markets indicate that the impact on incumbents' profitability seems to vary from media industry to media industry (Latzer et al. 2014). For example, in the news industry, algorithmic selection tends to decrease average profitability overall. Although incumbents benefit from added traffic streams (Chiou and Tucker 2013; Dellarocas et al. 2013) and from integrating algorithmic selection (e.g., news created by algorithms) as an ancillary function, intermediaries such as news aggregators or advertising networks change the forces of the industry to the disadvantage of incumbents. Increasingly high concentration in these markets is shifting the bargaining power to these intermediary platforms and allowing them to amplify their market power. This is especially the case if they are able to establish themselves as bottleneck monopolists that control the access to products of others (Shelanski 2013), as in the case of news publishers' content or as evident in the struggles between the bookselling industries, and lately Disney, and Amazon. Some have turned to opt-out options, e.g., by blocking their sites for search engines (e.g., News Corp. blocked Google services by using robot.txt files). Opting out of search services has not been a feasible solution for publishers, however. Search engines, for example, are responsible for high visitor streams to news websites, with widely differing figures up to $35 \%$ (SimilarWeb.com 2013). Further, aggregation of news in single access points also results in lower transaction and switching costs for news customers and tends to increase their bargaining power. As new entrants, online advertising networks in particular are straining incumbents' profitability. 
For the music industry, in contrast, it can be argued that algorithmic selection tends to increase incumbents' profitability overall, as music-streaming services (e.g., Last.FM, Spotify) strongly stimulate (legal) music consumption and have been revenue drivers in recent years. Although they also established themselves as intermediaries they are faced with a highly concentrated music industry with great bargaining power.

The differences in impact on various media industries can be explained by different business models of algorithmic selection services (market makers, layer players) and by the different stages of market development (market phases) of the relevant algorithmic selection services as well as business models and market structures of traditional industries (Latzer et al. 2014).

These first rough estimates and theoretical considerations of the possible impact of algorithmic selection on media industries still need further research, and in particular need to be combined and weighed with current market data in order to receive an accurate picture of the real economic implications for media industries.

\subsection{Social risks}

Algorithmic selection and attendant personal data collection have become objects of public concern and have raised questions about their impact on society as well as the need for public policy. Generally, the assessment of risks is an appropriate method to relate estimated economic and social benefits to risks, for example, the benefits gained by search engines in managing information overflow versus the risk to user privacy. A first step in such analysis is generally to identify possible risks and benefits and assess the probability of their occurrence and the number of people affected (e.g., how many people or institutions use an algorithmic application? Do these people or institutions have a multiplying effect? How often and how intensively do people/institutions use the application?).

The various risks of algorithmic selection applications found in the literature are here grouped in three overlapping categories, which in particular indicate that such analysis not only touches upon cost-benefit calculations but also extends into ethical/moral value judgments as well: (1) threats to basic rights and liberties, (2) impacts on the mediation of reality, and (3) challenges to the future development of the human species. Overall, eight specific risks can be distinguished that accompany the diffusion of algorithmic selection: (1) manipulation, (2) diminishing variety, the creation of biases and distortions of reality, (3) constraints on the freedom of communication and expression, (4) threats to data protection 
and privacy, (5) social discrimination, (6) violation of intellectual property rights, (7) possible transformations and adaptations of the human brain, and (8) uncertain effects of the power of algorithms on humans, e.g., growing independence of human control and growing human dependence on algorithms.

Empirical examples of manipulation are 'Google bombs' (e.g., Bar-Ilan 2007), described as planned massive influence on search results, or the improvement of websites through search-engine optimization. Manipulations have also been identified for recommender and reputation systems for goods and services such as hotel or product recommendations (e.g., Rietjens 2006; Schormann 2012). Algorithmic selection is furthermore associated with bias inasmuch as it is presumed to develop an algorithmic reality where content is only visible when it is produced and shaped according to the rules that algorithmic selection prescribes (Zhang and Dimitroff 2005; Cushing Weigle 2013). The rules themselves leave out certain aspects of reality and have incorporated specific values that unknowingly discriminate against particular content. Qualified empirical evidence for this phenomenon is rare, but various authors have discussed the self-enforcing mechanisms of algorithms and their biasing effects (e.g., filter bubble, Pariser 2011), or the creation of a digital divide on a content and usage level (Segev 2010). Accordingly, the much-discussed media realities reach a new level, leading to discussions about algorithmic realities that follow different, increasingly automated and commercialized rules.

Constraints on the freedom of communication are also identified as a possible risk of algorithmic selection - an argument derived largely from its technological design. As the name implies, it has a selective element that can be shaped, with differing effects, however. On the one hand it can be used to gain access to relevant content or to protect IP rights or to keep children from accessing harmful content (Hinman 2005). On the other hand, algorithmic selection may be adopted to diminish the democratic potential of digital media by being used for censorship (Zittrain and Palfrey 2008).

To fulfill their role as information intermediaries and information brokers, algorithmic selection applications have to rely on content produced by third parties and on data produced by consumers. Both sources of information involve certain risks. It is argued that, without infringing the intellectual property rights of content producers and distributors, many applications such as search engines, information aggregators or recommender systems would have no data basis on which to build their services (Stühmeier 2011). This kind of use of third-party content has led to disputes over copyright and other intellectual property rights, and publishers all over the world have sued Google for infringing such laws (Clark 2010, 
2012; Chiou and Tucker 2013; Quinn 2014). Moreover, many algorithmic selection applications are personalized/customized applications, i.e. applications that use data collected from the users to personalize results. This incorporates great risks concerning users' privacy and data protection. Today, personal data has become the new oil for the economy (World Economic Forum 2011b) and operators of algorithmic selection applications are major collectors of such data online. They use these data to customize services and monetize them (as an exchange for other/more data or by selling them directly) - activities that have resulted in various data privacy challenges (Chaleppa and Sin 2005; Zimmer 2008; Xu et al 2011; Toch et al. 2012). Algorithmic applications also raise debates concerning their influence on human cognitive abilities - a pressing object for future research. Current discussions range between questions of whether these applications result in the loss of abilities (Carr 2010; Henig and Henig 2012) or whether they are simply helping in allocating cognitive resources more efficiently, like other technologies in history (Sparrow 2011). Finally, there is a general discussion on how the relationship between humans and algorithms can be described and how this man-machine relationship will develop or should be shaped in the near future (Bunz 2012; Schirrmacher 2013). This includes questions about the power of algorithms, about whether humans are still able to control them or to what extent they control human behavior and development.

There are economic motives that promote major risks such as manipulation, threats to privacy or the infringement of IP laws. These motives are mainly predicated on efforts to maintain and amplify market power, e.g., by prioritizing one's own services in search results and excluding others - a concern that has raised discussions of whether search results should be subject to a search neutrality principle (Lao 2013), for example. Systematic manipulation is said to be mainly applied where goods, services and information are sold, or where trust in transactions needs to be built (e.g., deceptive recommendations). Major groups affected are search engines and recommender systems. New markets of manipulation evolved around algorithmic applications, such as search-engine optimization and marketing agencies as well as web-content-production agencies. In the meantime, they have become a vital and essential branch of the rapidly growing e-commerce sector.

Altogether, the production of economic wealth by algorithmic selection co-evolves with the emergence of social risks. Algorithmic selection leads to a commercialization/economization of automated reality mining and construction. The construction of realities - well known from research on traditional media - is not only automated by algorithmic selection and extended to further aspects of life but at the same time 
increasingly oriented on economic and less on social rationales. As a consequence of these increasingly automated and commercialized mining and formations of realities on the Internet, certain forms of governance seem to be necessary and are being discussed in order to realize the economic and social welfare goals anticipated by algorithmic selection.

\subsection{Risk reduction by market solutions and governance choice: opportunities and limitations}

There are two perspectives on governance and algorithms: governance $b y$ algorithms refers to the above-mentioned power of technology and the ability of algorithms to shape society; governance of algorithms refers to the practices to control, shape and regulate algorithms. In connection with the increasing awareness of risks, the opportunities for a social shaping of algorithmic selection by means of governance have attracted increased attention, most prominently the governance of search applications (e.g., Moffat 2009; Langford 2013; Lewandowski 2014). Further, disputes on certain practices and implications of news aggregation, search and algorithmic trading have resulted in regulatory provisions such as the German ancillary copyright law (BGB1. 2013, part 1, no. 23, p. 1161), the right to be forgotten for search engines in the EU (ECJ, judgment C-131/12 Google Spain vs. AEPD and Mario Costeja Gonzalez), and measures to prevent stock market crashes caused by algo trading, e.g., the European Markets in Financial Instruments Directive (MiFID 2, 2014/65/EU).

This section discusses justifications, opportunities and limitations for the governance of algorithmic selection. From a public-interest point of view, governance should reinforce benefits and minimize risks. Benefits and risks are tightly interlinked, because risks are central barriers for the exploitation of potential benefits. Accordingly, a 'risk-based approach' (Black 2010) examines the risks and explores the opportunities and limitations to reduce them. There are various arrangements to reduce risks and increase the benefits of algorithmic selection, ranging from market mechanisms at one end, to command and control regulation by state authorities at the other (Latzer et al. 2002; 2003). In between there are several additional governance options: self-organization by individual companies; (collective) industry selfregulation; and co-regulation - regulatory cooperation between state authorities and the industry. The subsequent analyses of opportunities and limitations of governance options reveal that there are no one-size-fits-all solutions for the governance of algorithms. Moreover they show that governance of algorithms does not just mean regulating the actual code, the technology itself (Brown and Marsden 2013). More often, the primary targets of governance 
interventions are organizational settings, e.g., the business models in the case of the ancillary copyright, with direct ramifications for the economics of the markets concerned. And finally, the analyses indicate that adequate governance strategies do not solely rely on one type of actor (e.g., the state, an industry association or companies), but often call for an interplay between the various levels and actors involved.

\subsubsection{Market solutions: risk-reduction strategies by consumers, content providers and suppliers}

Not all risks of algorithmic selection necessarily call for regulation. Risks may also be reduced by (voluntary) changes in the market conduct of consumers, suppliers of algorithmic services and by providers of the content that is processed by algorithms.

Consumers and providers of content may refrain from using problematic services, switch to other service providers or make use of technologies to protect themselves against risks. There are, for instance, technical self-help solutions for consumers in the case of censorship, bias and privacy violations, e.g., tools for anonymization and de-personalization of services. Content providers could avoid violations of copyright by using robots.txt files. In areas like search, recommendation and filtering, a digital arms race is observable, where market participants are trying to avoid disadvantages by using content-optimization strategies (Wittel and $\mathrm{Wu}$ 2004; Jansen 2007). Insights from behavioral economics applied to the Internet of things might help in understanding the motivations and practice of market participants for using technological design for self-help (Fleisch 2010). Moreover, public awareness campaigns regarding risks of algorithmic selection (governance by information) might support a more risk sensible market conduct.

However, there are also several limitations to self-help for consumers and content providers. Algorithmic applications often work without explicit consent and opt-out possibilities, e.g., from state and company surveillance programs. Switching service providers requires the existence of alternative services, but several markets are highly concentrated. If there are hardly any alternative suppliers, the switching opportunities are limited. For consumers, information asymmetries often make the risks of algorithmic selection barely visible, hence a direct motivation for consumer reaction is missing. Moreover, the usage of algorithmic services is mostly a low cost situation for users, because services are crosssubsidized by advertising. The absence of costs decreases the incentives to switch to lowerrisk alternatives. Finally, behavioral economics point out that even if costs and risks are detectable, consumers often do not carefully calculate the precise costs and benefits of their 
decisions (bounded rationality). Instead they rely on cognitive biases, which not always increase their long-term benefits, e.g., regarding the self-protection of privacy (Acquisti and Grossklags 2005).

Suppliers of algorithmic selection services may counter risks by product innovations, i.e. with new services or technological modifications of established ones. In such a case, the reduction of risks is part of the business strategy. There are, for example, services that aim at avoiding bias and violations of privacy and copyright in the first place. Some news aggregators' business models integrate content providers, who receive compensation (e.g., nachrichten.de). Other algorithmic services do not collect user data (e.g., the search engine DuckDuckGo). Services such as ConsiderIt, Reflect and OpinionSpace are designed to avoid filter bubbles and bias and integrate elements of serendipity (Munson and Resnick 2010; Schedl et al. 2012; Resnick et al. 2013). To increase privacy standards, services may apply privacy by default and privacy by design on the technological level (Schaar 2010; Cavoukia 2012). But there are also several limitations on the reduction of risks by market strategies of service suppliers. There are high entry barriers in some market segments, and the conditions for newcomers and product innovations are difficult. Low-risk alternatives are mostly niche products with a very limited number of users and the reduction of risks may be accompanied by a quality reduction. Moreover, a low number of users and reduced quality may mutually reinforce each other and further decrease the attractiveness of niche services. Altogether, for the reduction of risks it is not advisable to rely on market forces only.

\subsubsection{Self-organization by individual companies}

Individual suppliers of algorithmic services may reduce risks or strengthen their accountability by means of 'self-organization'. Typical measures are principles and standards, which reflect the public interest, internal quality assessment and ombudsmen at the corporate level. The commitment to self-organization is often part of a broader corporate social responsibility (CSR) strategy. From an economic point of view the purpose is to increase a company's reputation or to avoid reputation losses.

Suppliers of algorithmic services can commit themselves to certain 'values' (Introna and Nissenbaum 2000), such as search neutrality or the minimum principle for data collection for instance (Langheinrich 2001; Cavoukia 2009). Ethic boards may be an option for issues with ethical implications such as software development or interferences with user experience. For risks such as censorship, discrimination, bias and manipulation, companies may further 
adopt principles and internal quality control. Qualified personnel are essential for quality assessment and conflict resolution. For big data, in-house algorithmists have been suggested to oversee big-data operations, and who would be the first points of contact for people who feel harmed by an organization's big-data predictions (Mayer-Schönberger and Cukier 2013). Additionally, more transparency is one of the strategies to better inform consumers and facilitate the market mechanism, because the lack of transparency is one of the reasons for market failure in the area of algorithmic selection.

However, several potential barriers may inhibit voluntary measures at company level. Self-organization depends on incentives, i.e., benefits and cost for the company. However, the benefits of high standards of data protection (Hustinx 2010; London Economics 2010) and of the disclosure of the codes/algorithms may be limited. Disclosure would increase transparency, but also the danger of manipulation and imitation, resulting in the 'transparency dilemma' (Rieder 2005; Bracha and Pasquale 2008; Granka 2010). The willingness for selfrestrictions also depends on reputational factors. High levels of public attention on wellknown companies in $\mathrm{B} 2 \mathrm{C}$ markets may promote self-organization in the public interest. Google, for instance, runs an ethics board at the company level (Lin and Selinger 2014). Little public awareness of companies in B2B markets, such as dater brokers (e.g., Acxiom, Corelogic and Datalogix; see FTC 2014) reduces the reputational sensitivity and therefore also the preconditions for voluntary self-organization. Finally, the suitability of selforganization depends on the type of risk. It is not suitable, for example, for reducing problems like market concentration and transformations of cognitive capabilities.

\subsubsection{Self-regulation by the industry}

Self-regulation refers to collective self-restrictions of a branch in order to pursue public objectives. Typical instruments are codes of conduct, industry standards, quality seals and certification bodies, ombudsman schemes and ethic committees.

There are sectoral initiatives of self-regulation in the advertising industry (e.g., USA, Europe), the search engine market (e.g., Germany), social online networks (e.g., Europe) and in the domain of algo trading. These initiatives deal with risks such as violations of privacy and copyright, manipulation and controllability. In the advertising industry there are initiatives for the technical standardization of do-not-track (DNT) and for better data protection in the area of online behavioral advertising (OBA). Additionally, there are organizational and technical industry standards for the protection of copyright, e.g., the creative commons licensing system and digital rights management systems (DRM). 
Moreover, certification schemes, ombudsmen and ethics commissions seem to be appropriate instruments for dealing with controversial issues such as bias, manipulation, restrictions on communications and controllability of applications. However, these options have hardly been taken up by the industry so far.

There are reasons why self-regulation for algorithmic selection has not yet been comprehensively applied and suggestions as to how the conditions could be improved. Algorithmic selection is applied in a wide range of sectors. Due to the large number and the heterogeneity of the branches involved a common overall self-regulatory initiative is unlikely. In order to get a grip on fragmentation the establishment of a profession of 'algorithmists' and special professional rules and ethics have been suggested (Meyer-Schönberger and Cuckier 2013). However, there are additional factors that inhibit self-regulation. For instance, selfregulation is more likely to occur in mature industries with like-minded market players. But some of the markets are rather new (e.g., algorithmic content production) and often the developers of algorithmic solutions want to challenge established players and do not voluntarily comply with older industry schemes. Minimum standards that apply to all market participants would then have to be introduced by statutory regulation. In particular, selfregulation is not suitable in cases where there is a sharp divergence between public and private interests, and where damage in the case of regulatory failure would be high (Latzer 2007; Saurwein 2011).

\subsubsection{Co-regulation and state regulation}

The limitations of market mechanisms and self-regulation in reducing the risks can provide reasons and justifications for state intervention in algorithmic selection. Typical instruments of state intervention are: command and control regulation, incentives by subsidies/funding and taxes/fees, soft law and information measures.

In practice there are several examples of state influence in the domain of algorithmic selection, and regulations are related to particular risks rather than to a certain sector or a special technology. There are command and control regulations for violations of privacy and copyright, freedom of expression and fair competition. For example, in Europe, the privacy protection directive (95/46/EC, Art. 15) protects people against automated individual decisions on certain personal aspects such as performance at work, creditworthiness, reliability and conduct. In the area of privacy protection the development of privacyenhancing technologies (PETs) is funded by the EU, and some have even suggested introducing a data fee/tax in order to decrease the economic incentives for data collection 
(Lanier 2013, Collin and Colin 2013). Co-regulation has been established with the safeharbor principles and with data protection certification schemes and seals of quality. Another area of ongoing regulatory debate is search. Due to concerns regarding fair competition, Google was the subject of investigations by US and European competition authorities, because competitors claimed that a Google search gives undue preference to the company's other services. Some regulatory suggestions for the search-engine market aim at increased transparency and controllability by public authorities (e.g. algorithm disclosure requirements), while others propose cutting the barriers to market entry (Schulz et al. 2005). A publicly funded 'index of the web' (Lewandowski 2014) or user data sets (Argenton and Prüfer 2012) are suggested to be common resources in order to enhance market contestability, facilitate market entry and promote competition. Altogether, state intervention is multifaceted in the area of data protection, and there are many suggestions for regulating searches. But state intervention does not apply to all the problems of algorithmic selection. As for risks such as bias, uncontrollability and effects on cognitive capabilities, for instance, there are hardly any measures or suggestions for state intervention via regulation. In some of these areas it might be helpful to promote consumer awareness (governance by information), enhance user media literacy and stimulate conscious usage and self-protection abilities. Since algorithmic selection also involves ethical concerns, political actors may consider the appointment of ethical committees with broad stakeholder involvement to deal with conflicting values. It is evident that not all types of risk are suited to state intervention and when it comes to regulatory choice one also has to bear in mind the disadvantages of state regulation as compared to self-regulation, e.g., higher regulatory costs to the state, lower regulatory flexibility, and lower industry commitment to comply with regulations (Latzer et al. 2002; Bartle and Vass 2005).

\subsection{Conclusion}

This paper offers an innovation-co-evolution-complexity perspective on algorithmic selection on the Internet, a rapidly growing phenomenon, characterized by automated selection of information elements and the assignment of relevance to them. Algorithmic selection automates the commercialization of reality mining and reality construction in a fast growing number of fields of life in information societies. This radical and potentially disruptive bundle of innovations has far-reaching economic implications for existing and emerging markets. It challenges traditional business strategies, guides our actions and thereby influences economic success or failure. The production of economic wealth by algorithmic selection co-evolves 
with the production of social risks and with governance efforts that try to curb risks and thereby boost socio-economic welfare gains. This paper proposes a typology that covers nine categories including search, aggregation, recommendation, surveillance, allocation and scoring applications and describes their operation with a basic input-throughput-output model. Although these services share a common basic functionality, their modes of operation as well as their economic and social implications differ in detail.

Applications are in different market phases. Many services are still in an experimental phase, others in the expansion or stagnation phase and show impressive growth rates or high market sizes respectively. A combination of various industrial economic characteristics (e.g., cost structures, scale and scope economies, direct and indirect network effects) and the availability of essential core resources (e.g., technical expertise, hardware infrastructure, access to and quality of data) facilitate concentration tendencies and the subsequent preservation and amplification of market power.

Comparative business model analyses of algorithmic selection applications reveal similarities in services offered to end users, resulting in part from market characteristics (e.g., pricing in two- or multisided markets) or from imitation strategies. Services for business and public service customers, on the other hand, vary more widely, because they are frequently custom-made for specific purposes.

Algorithmic selection promises to reduce various kinds of transaction costs (e.g., search and information costs, information asymmetries) and as a result increases consumption and sales, and facilitates social orientation. Providers of algorithmic selection are mostly active as market makers (intermediaries) or layer players (specialists), and less as orchestrators or integrators. Revenues strategies in these markets depend on the fact that algorithmic selection applications often serve different, interdependent customer segments in two- or multi-sided markets, where prices have to be weighted accordingly and crosssubsidizing is indispensible. As a result, indirect forms of revenue predominate.

The effects on traditional media incumbents' profitability vary from industry to industry. Theoretical considerations indicate a tendency to decreasing profitability for incumbents of the news industry and a tendency towards a profitability increase in the music industry, as music-streaming services have been pushing revenues of the traditional music industry and have enhanced legal music consumption.

Products and services based on algorithmic selection have become vital and essential for the generation of economic wealth but are also compromised by the production of social risks, among other things, threats to basic rights and liberties as well as impacts on the 
mediation of realities and people's future development. The emergence of social risks is coupled with discussions of whether and what governance approaches are appropriate to remedy such risks. Analyses indicate that there are no one-size-fits all solutions, and that there is the need for a governance mix consistent with the respective risks and applications in questions. Adequate governance strategies often call for an interplay between the various levels and actors involved (e.g., self-help of consumers depends, among other things, on organizational or technical dispositions). Finally, governance measures are not only directed towards the algorithms (technical design) alone, but predominantly target organizational settings, e.g. the business models and strategies, with far-reaching effects for the economics of the markets concerned.

\section{References}

Acquisti, A. and J. Grossklags (2005), 'Privacy and rationality in individual decision making', IEEE Security \& Privacy, 3 (1), 26-33.

Aguila-Obra, A. R., A. Pandillo-Meléndez and C. Serarols-Tarrés (2007), 'Value creation and new intermediaries on Internet. An exploratory analysis of the online news industry and the web content aggregators', International Journal of Information Management, 27 (3), 187-199.

Anderson, C. W. (2013), 'Towards a Sociology of Computational and Algorithmic Journalism', New Media \& Society, 15 (7), 1005-1021.

Argenton, C. and J. Prüfer (2012), 'Search Engine Competition with Network Externalities', Journal of Competition Law \& Economics, 8 (1), 73-105.

Ashton, K. (2009), 'The ,Internet of Things' Thing', RFID Journal, available at http://www.itrco.jp/libraries/RFIDjournalThat\%20Internet\%20of\%20Things\%20Thing.pdf (accessed 23 July 2014).

Athey, S. and M. Mobius (2012), 'The Impact of News Aggregators on Internet News Consumption: The Case of Localization', online available http://www.markusmobius.org/sites/default/files/localnews.pdf (accessed 12 August 2014).

Banbura, M., D. Giannone and L. Reichlin (2010), 'Nowcasting', Working Paper Series European Central Bank, online availablehttp://www.ecb.europa.eu/pub/pdf/scpwps/ecbwp1275.pdf (accessed 12 August 2014).

Bar-Ilan (2007), 'Google Bombing from a Time Perspective', Journal of Computer-Mediated 
Communication, 12 (3), 910-938.

Bartle, I. and P. Vass (2005), 'Self-regulation and the Regulatory State. A Survey of Policy and Practice', University of Bath School of Management.

Beinhocker, E. (2006), 'The Origin of Wealth: Evolution, Complexity, and the Radical Remaking of Economics', Boston: Harvard Business School Press.

Benkler, Y. (2006), 'The Wealth of Networks. How Social Production Transforms Markets and Freedom', New Haven, London: Yale University Press.

Bergmann, D. and A. Bonatti (2011), 'Targeting in advertising markets: Implications for online versus offline media', RAND Journal of Economics, 42 (3), 417-443.

BGB1. 2013, Teil 1, Nr. 23, S. 1161 online available http://www.bgbl.de/banzxaver/bgbl/start.xav?startbk=Bundesanzeiger_BGB1\&jumpTo= bgb1113s1161.pdf (accessed 12 August 2014).

Black, J. (2010), 'Risk-based regulation: choices, practices and lessons learnt', in OECD: Risk and Regulatory Policy: Improving the Governance of Risk, Paris: OECD, pp. 185-224.

Bostic, R. W. and P. S. Calem (2003), 'Privacy Restrictions and the Use of Data at Credit Registries', in M. J. Miller (ed), Credit Reporting Systems and the International Economy, Palantino: MIT Press.

Bracha, O and F. Pasquale (2008), 'Federal Search Commission? Access, Fairness and Accountability in the Law of Search', Cornell Law Review, 93 (6), 1149-1210.

Bresnahan, T. (2010), 'General purpose technologies', in B. Hall and N. Rosenberg (eds), Handbook on the Economics of Innovation, Vol. 2, Amsterdam: Elsevier, pp. 761-791.

Brown, I. and C. Marsden, (2013), 'Regulating Code. Good Governance and Better Regulation in the Information Age.' Cambridge, M.A., London: MIT Press.

Bunz, M. (2012), 'Die stille Revolution', Berlin: Suhrkamp.

Calin, M., C. Dellarocas, E. Palme and. J. Sutanto (2013), 'Attention Allocation in Information-Rich Environments: The Case of News Aggregtaors', Boston U. School of Management Research Paper No. 2013-4, online available http://papers.ssrn.com/sol3/papers.cfm?abstract_id=2225359 (accessed 12 August 2014).

Carr, N. (2010), 'The Shallows: What the Internet is Doing to Our Brains', New York: W. W. Norton.

Cavoukia, A. (2009), 'Privacy by Design', Lecture at the Trust Economics Workshop, London June 23, 2009, online available http://www.ipc.on.ca/images/Resources/200906-23-TrustEconomics.pdf (accessed 12 August 2014). 
Cavoukia, A. (2012), 'Privacy by Design: Origins, Meaning, and Prospects for Ensuring Privacy and Trust in the Information Era', online available http://www.privacybydesign.ca/content/uploads/2010/03/PrivacybyDesignBook.pdf (accessed 12 August 2014).

Chaleppa, R. K. and R. G. Sin (2005), 'Personalization versus Privacy: An Empirical Examination of Online Consumer's Dilemma', Information, Technology and Management, 6 (2-3), 181-202.

Chiou, L. and C. Tucker (2013), 'Digitization and Aggregation', online available http://bellarmine.lmu.edu/media/lmubellarminesite/bcladepartments/economics/econom icsdocuments/Digitization\%20and\%20Aggregation.pdf (accessed 12 August 2014).

Christensen, C. M. (1997), 'The innovators dilemma: When Technologies Cause Great Firms to Fail', Boston: Harvard Business Review Press.

Ciocchetti, C. A. (2011), 'The Eavesdropping Employer: A Twenty-First Century Framework for Employee Monitoring', American Business Law Journal, 48 (2), 285-369.

Clark, B. (2010), 'Google Image Search does not infringe copyright, says Bundesgerichtshof', Journal of Intellectual Property Law \& Practice, 5 (8), 553-555.

Clark, B. (2012), 'Google image still does not infringe copyright, reaffirms Bundesgerichtshof', Journal of Intellectual Property Law \& Practice, 7 (11), 788-789.

Collin, P. and N. Colin (2013), 'Mission d'expertise sur la fiscalité de l'économie numérique', online available http://www.redressement-productif.gouv.fr/files/rapportfiscalite-du-numerique_2013.pdf (accessed 16 August 2014).

Cormen, T. H., C. E. Leiserson, R. L. Rivest and C. Stein (2009), 'Introduction to Algorithms', Cambridge, Mass: MIT Press.

Cushing Weigle, S. (2013), 'English language learners and automated scoring of essays: Critical considerations', Assessing Writing, 18 (1), 85-99.

Deibert, R., J. Palfrey, R. Rohozinski and J. Zittrain (eds) (2008), 'Access Denied', Cambridge CA, London: MIT Press.

Deibert, R., J. Palfrey, R. Rohozinski and J. Zittrain (eds) (2010), 'Access Controlled', Cambridge CA, London: MIT Press.

Dellarocas, C., Z. Katona and W. M. Rand (2013), 'Media, Aggregators and the Link Economy', Management Science, 59 (10), 2360-2379.

Directive 2014/65/EU of the European Parliament and of the Council of 15 May 2014 on markets in financial instruments and amending Directive 2002/92/EC and Directive 2011/61/EU. Official Journal L 173, 12.6.2014, pp. 349-496. 
Directive 95/46/EC of the European Parliament and of the Council of 24 October 1995 on the protection of individuals with regard to the processing of personal data and on the free movement of such data. Official Journal L 281, 23.11.1995, pp. 31-50.

ECJ - European Court of Justice (2014), ECJ judgement C-131/12 Google Spain vs. AEPD and Mario Costeja Gonzalez, online available http://curia.europa.eu/jcms/upload/docs/application/pdf/2014-05/cp140070en.pdf (accessed 12 August 2014).

Edelmann, B., M. Ostrovsky and M. Schwarz (2005), 'Internet Advertising and the Generalized Second Price Auction: Selling Billions of Dollars Worth of Keywords', NBER Working Paper Series, online available http://www.nber.org/papers/w11765.pdf (accessed 12 August 2014).

eMarketer (2013), 'Google, Facebook Continue to Lead in Digital Display Earnings', online available http://www.emarketer.com/Article/Google-Facebook-Continue-Lead-DigitalDisplay-Earnings/1009769 (accessed 12 August 2014).

Evans, D. (2008), 'The Economics of the Online Advertising Industry', Review of Network Economics, 7 (3), 359-391.

Evans, D. (2009), ‘The Online Advertising Industry: Economics, Evolution and Privacy', The Journal of Economic Perspectives, 23 (3), 37-60.

Faigle, P. (2010), 'Googeln einmal anders', Zeit Online, online available http://www.zeit.de/2010/43/Google-Oekonomie-Indikator (accessed 24 July 2014).

Fleisch, E. (2010), 'What is the Internet of Things? An Economic Perspective', Auto-ID Labs White Paper WP-BIZAPP-053, online available http://cocoa.ethz.ch/media/documents/2014/06/archive/AUTOIDLABS-WP-BIZAPP53.pdf (accessed 18 August 2014).

FTC - Federal Trade Commission (2014), 'Data Brokers. A call for Transparency and Accountability', online available http://www.ftc.gov/system/files/documents/reports/data-brokers-call-transparencyaccountability-report-federal-trade-commission-may-2014/140527databrokerreport.pdf (accessed 12 August 2014).

Granka, L. A. (2010), 'The politics of search: A decade retrospective', The Information Society, 26 (5), 364-374.

Greenwald, G. and E. MacAskill (2013), 'NSA prism Program Taps in to User Data of Apple, Google and Others', The Guardian, online available http://www.theguardian.com/world/2013/jun/06/us-tech-giants-nsa-data (accessed 23 
July 2014).

Hanani, U., B. Shapira and P. Shoval (2001), 'Information Filtering: Overview of Issues, Research and Systems', User Modeling and User-Adapted Interaction, 11 (3), 203-259.

Henig, R. M. and S. Henig (2012), 'Twentysomething: Why Do Young Adults Seem Stuck?', New York: Hudson Street Press.

Heuskel, D. (1999), 'Wettbewerb jenseits von Industriegrenzen: Aufbruch zu neuen Wachstumsstrategien', Frankfurt: Campus Verlag.

Hinman, L. M. (2005), 'Esse est indicato in Google: Ethical and Political Issues in Search Engines', International Review of Information Ethics, 3 (6), 19-25.

Hinz, O. and J. Eckert (2010), 'The Impact of Search and Recommendation Systems on Sales in Electronic Commerce', Business \& Information Systems Engineering, 2 (2), 67-77.

Hustinx, P. (2010), 'Privacy by design: delivering the promises', Identity in the Information Society, 3 (2), 253-255.

Introna, L. D., H. Nissenbaum (2000), 'Shaping the Web: Why the politics of search engines matters', The Information Society, 16 (3), 169-185.

Isbell, K. (2010), 'The Rise of the News Aggregator: Legal Implications and Best Practices', Berkman Center for Internet \& Society Research Publication 2010-10, online available https://papers.ssrn.com/sol3/Data_Integrity_Notice.cfm?abid=1670339 (accessed 12 August 2014).

Issenberg, S. (2012), 'The Victory Lab', New York: Crown Publishers.

Jaeggi, M. (2010), 'Business Model Innovation in Wealth Management', Dissertation, St. Gallen University.

Jannach, D., M. Zanker, A. Felfernig and G. Friedrich (2011), 'Recommender Systems. An Introduction', Cambridge: Cambridge University Press.

Jansen, B. J. (2007), 'Click fraud', Computer, 40 (7), 85-86.

Jürgens, P., A. Jungherr and H. Schoen (2011), 'Small Worlds with a Difference: New Gatekeepers and the Filtering of Political Information on Twitter', ACM, online available http://dl.acm.org/citation.cfm?id=2527034 (accessed 12 August 2014).

Klahold, A. (2009), 'Empfehlungssysteme. Recommender Systems - Grundlagen, Konzepte, Lösungen', Wiesbaden: Vieweg + Teubner.

Klingenberg, B. (2000), 'Kundennutzen und Kundentreue. Eine Untersuchung zum TreueNutzen aus Konsumentensicht', Dissertation, University of Munich.

König, R. and M. Rasch (eds) (2014), 'Society of the Query Reader: Reflections on Web Search', Amsterdam: Institute of Network Cultures, online available 
http://networkcultures.org/blog/publication/society-of-the-query-reader-reflections-onweb-search/ (accessed 20 August 2014).

Küsters, U., B. D. McCullough and M. Bell (2006), 'Forecasting software: Past, present and future', International Journal of Forecasting, 22 (3), 599-615.

Langford, A. (2013), 'gMonopoly: Does Search Bias Warrant Antitrust or Regulatory Intervention?', Indiana Law Journal, 88 (4), 1559-1592.

Langheinrich, M. (2001), 'Privacy by Design — Principles of Privacy-Aware Ubiquitous

Systems', in G. D. Abowd, B. Brumitt and S. A. Shafer (eds), Proceedings of the Third International Conference on Ubiquitous Computing (UbiComp 2001), Lecture Notes in Computer Science (LNCS), Volume 2201, pp. 273-291.

Lanier, J. (2013), 'Who owns the future?', New York: Simon and Schuster.

Lao, M. (2013), “'Neutral' Search as a Basis for Antitrust Action?', Harvard Journal of Law \& Technology, 26 (2), 1-12.

Latzer, M. (2007), 'Regulatory Choice in Communications Governance', Communications The European Journal of Communication Research, 32 (3), 399-405.

Latzer, M. (2013a), 'Medienwandel durch Innovation, Ko-Evolution und Komplexität. Ein Aufriss', Medien und Kommunikationswissenschaft, 61 (2), 235-252.

Latzer, M. (2013b), 'Towards an Innovation-Co-evolution-Complexity Perspective on Communications Policy', in M. Löblich and S. Pfaff-Rüdiger (eds), Communication and Media Policy in the Era of Digitization and the Internet, Baden-Baden: Nomos, pp. $15-27$.

Latzer, M. (2014), 'Convergence, Co-evolution and Complexity in European Communications Policy', in K. Donders, C. Pauwels and J. Loisen (eds), The Palgrave Handbook of European Media Policy, Houndmills: Palgrave Macmillan, pp. 36-53.

Latzer, M., J. Gewinner, K. Hollnbuchner, N. Just and F. Saurwein et al. (2014), 'Algorithmische Selektion im Internet. Ökonomie und Politik automatisierter Relevanzzuweisung in der Informationsgesellschaft', Forschungsbericht: Universität Zürich, IPMZ, Abteilung für Medienwandel \& Innovation.

Latzer, M., N. Just, F. Saurwein and P. Slominski (2002), 'Selbst- und Ko-Regulierung im Mediamatiksektor. Alternative Regulierungsformen zwischen Markt und Staat', Wiesbaden: Westdeutscher Verlag.

Latzer, M., N. Just, F. Saurwein and P. Slominski (2003), 'Regulation Remixed: Institutional Change through Self and Co-Regulation in the Mediamatics Sector', Communications $\&$ Strategies, 50 (2), 127-157. 
Lee, J. (ed) (2007), ‘Algorithmic Trading: A Buy-side Handbook', London: The Trade.

Leinweber, D. (2009), 'Nerds on Wallstreet. Math, Machines and Wired Markets', Hoboken: John Wiley \& Sons.

Levy, S. (2012), 'Can an Algorithm Write a Better News Story Than a Human Reporter?', Wired, online available http://www.wired.com/2012/04/can-an-algorithm-write-abetter-news-story-than-a-human-reporter/ (accessed 20 August 2014).

Lewandowski, D. (2014), 'Why We Need an Independent Index of the Web', in R. König and M. Rasch (eds), Society of the Query Reader: Reflections on Web Search, Amsterdam: Institute of Network Cultures.

Lewandowski, D. (ed) (2012), 'Web Search Engine Research', Bingley: Emerald.

Lin, P. and E. Selinger (2014), 'Inside Google's Mysterious Ethics Board', Forbes, online available http://www.forbes.com/sites/privacynotice/2014/02/03/inside-googlesmysterious-ethics-board/ (accessed 15 September 2014).

London Economics (2010), 'Study on the economic benefits of privacy enhancing technologies (PETs)', Final Report to the European Commission DG Justice, Freedom and Security, online available http://ec.europa.eu/justice/policies/privacy/docs/studies/final_report_pets_16_07_10_en .pdf (accessed 12 August 2014).

Lyon, D. (2003), 'Surveillance as social sorting: computer codes and mobile bodies', in D. Lyon (ed), Surveillance as Social Sorting. Privacy, risk, and social discrimination. London, New York: Routledge, pp. 13-30.

Maßß, C., A. Skussa,, A. Heß and G. Pietsch (2009), 'Der Markt für InternetSuchmaschinen', in D. Lewandowski (ed), Handbuch Internet-Suchmaschinen. Nutzerorientierung in Wissenschaft und Praxis, Heidelberg: Akademische Verlagsgesellschaft, pp. 3-17.

Machill, M. and M. Beiler (2007), 'Die Macht der Suchmaschinen - The Power of Search Engines', Köln: Herbert von Halem Verlag.

Mager, A. (2012), 'Algorithmic Ideology: How Capitalist Society Shapes Search Engines', Information, Communication \& Society, 15 (5), 769-787.

Mattern, F. and C. Floerkemeier (2010), 'From the Internet of Computers to the Internet of Things', in K. Sachs, I. Petrov and P. Guerrero (eds), From Active Data Management to Event-Based Systems and More, Berlin, Heidelberg: Springer, pp. 242-259.

Mayer-Schönberger, V. and K. Cukier (2013), 'Big Data. Die Revolution, die unser Leben verändern wird', München: Redline Verlag. 
McAfee, A. and E. Brynjolfsson (2012), 'Big Data: The Management Revolution', Harvard Business Review, 90 (10), 60-68.

Moffat, V. R. (2009), 'Regulating Search', Harvard Journal of Law \& Technology, 22 (2), 475-513.

Mössenböck, H. (2014), 'Sprechen Sie Java?', 5th rev. version, Linz: dpunkt Verlag.

Munson, S. A. and P. Resnick (2010), 'Presenting diverse political opinions: how and how much', Proceedings of ACM CHI 2010 Conference on Human Factors in Computing Systems 2010, 1457-1466.

Napoli, P. M. (2013), 'The Algorithm as Institution: Toward a Theoretical Framework For Automated Media Production and Consumption', Paper presented at the Media in Transition Conference at the MIT Cambridge, May 2013.

O’Reilly, T. (2007), 'What Is Web 2.0: Design Patterns and Business Models for the Next Generation of Software', Communications \& Strategies, 65 (1), 17-37.

OECD (2013), 'Exploring Data-Driven Innovation as a New Source of Growth. Mapping the Policy Issues Raised by 'Big Data', online available http://www.oecdilibrary.org/science-and-technology/exploring-data-driven-innovation-as-a-new-sourceof-growth_5k47zw3fcp43-en (accessed 23 July 2014).

Osterwalder, A., Y. Pigneur and C. L. Tucci (2005), 'Clarifying Business Models. Origins, Present, and Future of the Concept', Communications of the Association for Information Systems, 16 (1), 1-25.

Pariser, E. (2011), 'The Filter Bubble: What the Internet is Hiding from You', London (a.o.): Penguin Books.

Pathak, B. K., R. Garfinkel, R. D. Gopal, R. Venkathesan and F. Yin (2010), 'Empirical Analysis of the Businessvalue of Recommender Systems', Journal of Management Information Systems, 27 (2), 159-188.

Pavlov, E., J. S. Rosenschein and Z. Topol (2004), 'Supporting Privacy in Decentralized Additive Reputation Systems', in C. Jensen, S. Poslad and T. Dimitrakos (eds), Trust Management, Second International Conference, iTrust, Oxford, UK, March 29 - April 1, 2004, Proceedings: Springer, pp. 108-119

Porter, M. E. (2001), 'Strategy and the Internet', Harvard Business Review, 79 (3), 1-20.

Porter, M. E. (2008), 'The Five Competitive Forces that Shape Strategy', Harvard Business Review, 86 (1), 78-93.

Pridmore, J. and D. Zwick (2011), 'Editoral: Marketing and the Rise of Commercial Consumer Surveillance', Surveillance \& Society, 8 (3), 269-277. 
Pronk, V. et al. (2009), 'Personal Television Channels: Simply Zapping through Your PVR Content', online available http://repository.tudelft.nl/view/philips/uuid:293926ed-456248c0-bae3-1baa5939cdb7/ (accessed 21 August 2014).

Quinn, D. J. (2014), 'Associated Press v. Meltwater: Are Courts Being Fair to News Aggregators?', Minnesota Journal of Law, Science and Technology, 15 (2), 1189-1219.

Resnick, P. and H. Varian (1997), 'Recommender Systems', Commuications of the ACM, 40 (3), 56-58.

Resnick, P. and R. Zeckhauser (2002), 'Trust Among Strangers In Internet Transactions: An Empirical Analysis of eBay's Reputation System', in M. R. Baye (ed), The Economics of the Internet and E-commerce (Advances in Applied Microeconomics, Volume 11), Emerald Group Publishing Limited, pp. 127-157.

Resnick, P., R. K. Garrett, T. Kriplean, S. A. Munson and N. J. Stroud (2013), 'Bursting your (filter) bubble: strategies for promoting diverse exposure', Proceedings of the 2013 conference on Computer supported cooperative work companion, 95-100.

Ricci, F., L. Rokach, B. Shapira and P. B. Kantor (eds) (2011), 'Recommendation Systems Handbook', Heidelberg (a.o.): Springer.

Rieder, B. (2005), 'Networked control. Search engines and the symmetry of confidence', International Review of Information Ethics, 3, 26-32.

Rietjens, B. (2006), 'Trust and reputation on eBay: Towards a legal framework for feedback intermediaries', Information \& Communications Technology Law, 15 (1), 55-78.

Rip, A. (2007), 'Die Verzahnung von technologischen und sozialen Determinismen und die Ambivalenz von Handlungsträgerschaft im 'Constructive Technology Assessment', in U. Dolata and R. Werle (eds), Gesellschaft und die Macht der Technik, Frankfurt: Campus, pp. 83-106.

Robillard, M. P., W. Maalej, R. J. Walker and T. Zimmermann (eds) (2014), 'Recommendation Systems in Software Engineering', Heidelberg (a.o.): Springer.

Rochet, J.-C. and J. Tirole (2003), 'Platform Competition in Two-Sided Markets', Journal of the European Economic Association, 1 (4), 990-1029.

Rothmann, R., J. Sterbik-Lamina, W. Peissl (2014), 'Credit Scoring in Österreich', BerichtNr. ITA-PB A66, Wien: Institut für Technikfolgen-Abschätzung (ITA). http://epub.oeaw.ac.at/ita/ita-projektberichte/a66.pdf (accessed 25 September 2014)

Saurwein, F. (2011), 'Regulatory choice for alternative modes of regulation. How context matters', Law \& Policy, 33 (3), 334-366.

Schaar, P. (2010), 'Privacy by Design', Identity in the Information Society, 3 (2), 267-274. 
Schedl, M., D. Hauger and D. Schnitzer (2012), 'A model for serendipitous music retrieval', Proceedings of the 2nd Workshop on Context-awareness in Retrieval and Recommendation, 10-13.

Schirrmacher, F. (2013), ‘Ego. Das Spiel des Lebens’, München: Blessing.

Schormann, T. (2012), 'Online-Portale: Großer Teil der Hotelbewertungen ist manipuliert', Spiegel Online, online available http://www.spiegel.de/reise/aktuell/online-portalegrosser-teil-der-hotelbewertungen-ist-manipuliert-a-820383.html (accessed 12 August 2014).

Schulz, W., T. Held and A. Laudien (2005), 'Search Engines as Gatekeepers of Public Communication: Analysis of the German Framework Applicable to Internet Search Engines Including Media Law and Anti-trust Law', German Law Journal, 6 (10), 1418 1433.

Segev, E. (2010), 'Google and the Digital Divide. The bias of online knowledge', Oxford: Chandos Publishing.

Senecal, S. and J. Nantel (2004), 'The influence of online product recommendation on consumers' online choice', Journal of Retailing, 80 (2), 159-169.

Shelanski, H. A. (2013), 'Information, Innovation, and Competition Policy for the Internet', University of Pennsylvania Law Review, 161, 1663-1705.

Silver, N. (2012), 'The Signal and the Noise: Why So Many Predictions Fail - but Some Don't', New York: Penguin.

SimilarWeb (2013), online available http://www.similarweb.com/ (accessed 12 August 2014).

Sparrow, B., J. Liu and D.M. Wegner (2011), 'Google Effects on Memory: Cognitive Consequences of Having Information at Our Fingertips', Science, 333 (6043), 776-778.

Statista (2014), 'Leading dating websites in the United States in June 2014, based on visitor numbers (in millions)', online available http://www.statista.com/statistics/274144/mostpopular-us-dating-websites-ranked-by-monthly-visitors/ (visited 12 August 2014).

Steinbrecher, S. (2006), 'Design Options for Privacy-Respecting Reputation Systems within Centralised Internet Communities', in S. Fischer-Hübner, K. Rannenberg, L. Yngström and S. Lindskog (eds), Security and Privacy in Dynamic Environments, Proceedings of the IFIP TC-11 21st International Information Security Conference (SEC 2006), 22-24 May 2006, Karlstad, Sweden: Springer, pp. 123-134.

Steiner, C. (2012), 'Automate This: How Algorithms Came to Rule Our World', New York (a.o.): Penguin.

Stühmeier, T. (2011), 'Das Leistungsschutzrecht für Presseverleger: Eine ordnungspolitische 
Analyse', Ordnungspolitische Perspektiven, 12, 1-20.

Teece, D. J. (2006), 'Reflections on 'Profiting from Innovation', Research Policy, 35 (8), 1131-1146.

Teece, D. J. (2010), 'Business Models, Business Strategy and Innovation', Long Range Planning, 43 (2-3), 172-194.

Toch, E., Y. Wang and L. F. Crainor (2012), 'Personalization and privacy: a survey of privacy risks and remedies in personalization-based systems', User Modeling and UserAdapted Interaction, 22 (1-2), 203-220.

Van Dalen, A. (2012), 'The Algorithm Behind the Headlines. How machine-written news redefines the core skills of human journalists', Journalism Practice, 5 (5-6), 648-658.

Van Schewick, B. (2010), 'Internet Architecture and Innovation', Cambridge: MIT Press.

VanderMey, A. (2013), 'Outsourcing the algorithm of love to online dating', Fortune, online available http://fortune.com/2013/02/14/outsourcing-the-algorithm-of-love-to-onlinedating/ (accessed 12 August 2014).

Varian, H. (2006), 'Position Auctions: A theoretical and empirical analysis of the ad auction used by Google and Yahoo', International Journal of Industrial Organization, 25 (6), 1163-1178.

Varian, H. (2009), 'Online Ad Auctions', The American Economic Review, 99 (2), 430-434.

Wallace, J. and K. Dörr (2015), 'Beyond Traditional Gatekeeping. How Algorithms and Users Restructure the Online Gatekeeping Process', Conference Paper, Digital Disruption to Journalism and Mass Communication Theory, 2-3 October 2014, Brussels.

Weaver, A.B. (2013), 'Aggravated with Aggregators: Can International Copyright Law Help Save the Newsroom?', Emory International Law Review, 26 (4), 1159-1198.

Whitt, R. and S. Schultze (2009), 'The New 'Emergence Economics' of Innovation and Growth, and What It Means for Communications Policy', Journal on Telecommunications and High Technology Law, 7 (2), 217-316.

Wittel, G. L. and S. F. Wu (2004), 'On attacking statistical spam filters', Proceedings of the first conference on email and anti-spam (CEAS), online available http://pdf.aminer.org/000/085/123/on_attacking_statistical_spam_filters.pdf (accessed 12 August 2014).

World Economic Forum (2011a), 'Personal Data: The Emergence of a New Asset Class', online available http://www3.weforum.org/docs/WEF_ITTC_PersonalDataNewAsset_Report_2011.pdf 
(accessed 23 July 2014).

World Economic Forum (2011b), 'Personal Data: The 'New Oil' of the $21^{\text {st }}$ Century', online available http://www.weforum.org/sessions/summary/personal-data-new-oil-21stcentury (accessed 12 August 2014).

Xu, H., X. R. Luo, J. M. Caroll and M. B. Rosson (2011), 'The personalization privacy paradox: An exploratory study of decision making process for location-aware marketing', Decision Support Systems, 51 (1), 42-52.

Zhang, J. and A. Dimitroff (2005), 'The impact of webpage content characteristics on webpage visibility in search engine results (Part I)', Information Processing and Management, 41 (3), 665-690.

Zhu, H., M. D. Siegel and S. E. Madnick (2001), 'Information Aggregation: A Value-added E-Service', online available http://ebusiness.mit.edu/research/papers/106\%20SMadnick,\%20Siegel\%20Information \%20Aggregation.pdf (accessed 23 July 2014).

Ziman, J. (ed) (2000), ‘Technological Innovation as an Evolutionary Process', Cambridge: Cambridge University Press.

Zimmer, M. (2008), 'The Externalities of Search 2.0: The Emerging Privacy Threats when the Drive for the Perfect Search Engine meets Web 2.0', First Monday, 13 (3), online available http://www.firstmonday.dk/ojs/index.php/fm/article/view/2136/1944 (accessed 12 August 2014).

Zittrain, J. and J. Palfrey (2008), 'Internet Filtering: The Politics and Mechanisms of Control', in R. Deibert et al. (eds), Access Denied, pp. 29-56.

Zollenkopp, M. (2006), ‘Geschäftsmodellinnovation', Wiesbaden: Deutscher Universitätsverlag. 